\title{
Gene expression profiling induced by histone deacetylase inhibitor, FK228, in human esophageal squamous cancer cells
}

\author{
ISAMU HOSHINO, HISAHIRO MATSUBARA, YASUNORI AKUTSU, TAKANORI NISHIMORI, \\ YASUO YONEYAMA, KENTARO MURAKAMI, AKI KOMATSU, HARUHITO SAKATA, \\ KAZUYUKI MATSUSHITA and TAKENORI OCHIAI
}

Department of Frontier Surgery, Chiba University, Graduate School of Medicine, Chiba, Japan

Received March 31, 2007; Accepted May 29, 2007

\begin{abstract}
Histone deacetylase inhibitors (HDACIs) are promising therapeutic agents with the potential for regulating cell cycle, differentiation and apoptosis in cancer cells. HDACI activity is associated with selective transcriptional regulation and altering gene expression. However, the exact mechanisms leading to the antitumor effect of HDACIs are not fully understood. FK228, one of the powerful HDACIs, strongly inhibited cell growth of T.Tn and TE2 cells and induced apoptosis. Therefore, comprehensive analysis of the changes in gene expression in human esophageal cancer cell lines by the HDACI FK228 was carried out by microarray analysis. This analysis was used to clarify the expression profiles of genes after exposure to FK228. Of the 4,608 genes analyzed, 93 genes in T.Tn and 65 genes in TE2 were up- or down-regulated 2-fold or more at least at one time point during FK228 exposure and they were classified into four clusters based on their expression patterns. Among them, 15 genes were contained in both cell lines and their expression patterns were similar. Except p21, Prdx1 (reported by us) and IGFBP3, the behaviour/expression of 12 highly responsive genes has still not been reported in esophageal cancer cells. These observations of the expression patterns of functionally classified genes provided insights into the mechanism of the antitumor effect of FK228 in esophageal squamous carcinoma.
\end{abstract}

\section{Introduction}

Esophageal squamous cell carcinoma (ESCC) remains one of the intractable cancers due to its higher incidence in older patients and its rapid infiltration into neighboring tissues despite the recent progress in multi-modal approaches $(1,2)$. Currently, cisplatin and 5-fluorouracil are considered the

Correspondence to: Hisahiro Matsubara, Department of Frontier Surgery, Graduate School of Medicine, Chiba University, Inohana 1-8-1, Chuo-ku, Chiba 260-8670, Japan

E-mail: matsuhm@faculty.chiba-u.jp

Key words: histone deacetylase inhibitor, FK228, esophageal squamous cell carcinoma optimal chemotherapy agents for ESCC (3). However, the response rates of these combination chemotherapies are not satisfactory and the development of new anticancer drugs is expected to improve the prognosis of ESCC. Histone deacetylase inhibitors (HDACIs) are considered to represent one of the most promising agents for this purpose.

The balance of acetylation by histone acetylases and deacetylation by histone deacetylase prevents full acetylation, thereby creating a default underacetylated state. Acetylated histone tails and other chromosome-associated proteins have been identified in nucleosomes and shown to be important in regulating gene expression $(4,5)$. Histone acetylation is often associated with the transcription of gene characteristics of the differentiated state. In contrast, histone deacetylation correlates with transcriptional silencing and specifically, down-regulation of the expression of pro-apoptotic genes. The anticancer effects of HDACIs were mainly thought to be activated by the modulation of gene expression patterns including genes associated with cell cycle arrest and apoptosis by inhibiting HDAC activities. The induction of apoptosis by HDACIs via cell death pathways mediated by TRAIL, Fas, Bid and p53 was also reported (6-10). However, a comprehensive analysis of the expression profiles of these genes has not been reported.

FK228, one of the novel histone deacetylase inhibitors and isolated from chromobacterium violaceum, has exhibited remarkable antitumor activity in xenograft models and patients with cutaneous T-cell lymphoma had a complete or partial response in a phase I trial $(11,12)$. The current study was designed to explore the efficacy of the antitumor activity on human esophageal squamous cancer cell lines and to identify and characterize additional target genes of FK228. By using microarray analysis, we revealed gene expression profiles during the exposure of FK228 for up to $48 \mathrm{~h}$. Ninetythree genes in T.Tn and 65 genes in TE2 were shown to be regulated during the course of FK228 exposure. Among them, 15 genes showed substantial induction in both cell lines and their microarray analysis gave insights into the roles and regulation of genes by FK228.

\section{Materials and methods}

Assay of cytotoxicity. Cell growth was determined by Cell Counting Kit-8 (Dojindo, Kumamoto, Japan). $5 \times 10^{3}$ cells per well were seeded into 96-well microplates and incubated for 
$48 \mathrm{~h}$ at $37^{\circ} \mathrm{C}$ under $5 \% \mathrm{CO}_{2}$. FK228 was dissolved in ethanol and diluted with DMEM. After changing the medium, test samples were changed and incubated in the presence or absence of drugs for $72 \mathrm{~h}$. Then the Cell Counting Kit-8 reagent was added and allowed to react for $3 \mathrm{~h}$. Absorbance at $450 \mathrm{~nm}$ was measured using a microplate reader (Bio-Rad Laboratories, Hercules, CA). The IC50 (50\% inhibitory concentration) values were calculated by the least squares method.

$m R N A$ preparation and $c D N A$ microarray analysis. Cells were seeded into $225-\mathrm{cm}^{2}$ flasks and incubated for $48 \mathrm{~h}$, then treated with or without IC80 concentration of FK228 for up to $48 \mathrm{~h}$ and harvested at $0,6,12,24$ and $48 \mathrm{~h}$. Cells were washed with PBS and processed for RNA extraction with the RNeasy Kit (Qiagen Inc., Chatsworth, CA) according to the manufacturer's instructions. Total RNA $(20 \mu \mathrm{g})$ from cells cultured with FK228 was compared with $20 \mu \mathrm{g}$ of total RNA from cells cultured without FK228, using the cDNA microarray, which consisted of 4608 distinct cDNA clones, generated as described previously (13). Fluorescent images of the hybridized microarrays were scanned with a fluorescence laser confocal slide scanner (Scan Array 4000, GSI Lumonics, Nepean, Canada) and analyzed with Quant Array software (GSI Lumonics, Nepean, Canada) according to the manufacturer's instructions. All experiments were done in duplicate and averaged data for each of the time points were subjected to statistical analysis. To identify genes significantly expressed, we defined the data for those genes that showed 2 -fold changes for at least one time point.

Real-time quantitative RT-PCR. The expression changes of 5 randomly selected genes (prohibitin, S100A6, ZNF24, EIF4A1, cyclin I) were also examined by real-time quantitative PCR using the Light Cycler technique (Roche Diagnostics GmbH, Mannheim, Germany). The cDNA templates for real-time PCR were synthesized from $1 \mu \mathrm{g}$ of total RNA using SuperScript II reverse transcriptase and an oligo-dT primer. The glyceraldehyde-3-phosphate dehydrogenase (GAPDH) gene served as an internal control. The PCR reaction consisted of DNA Master SYBR-Green I mix (Light Cycler-FastStart DNA Master SYBR-Green I kit, Roche Diagnostics; containing Taq DNA polymerase, dNTP, $3 \mathrm{mM} \mathrm{MgCl}_{2}$ and SYBR-Green dye), $0.5 \mu \mathrm{M}$ each primer and cDNA. The PCR processes were as follows: initial denaturation at $95^{\circ} \mathrm{C}$ for $10 \mathrm{~min}$, followed by 45 cycles of denaturation at $95^{\circ} \mathrm{C}$ for $15 \mathrm{sec}$, annealing at $57^{\circ} \mathrm{C}$ for $10 \mathrm{sec}$ and elongation at $72^{\circ} \mathrm{C}$ for $8-18 \mathrm{sec}$. The Fit Points method provided by the Light Cycler software was used to estimate the concentration of each sample. Primers were chosen using Primer 3 (available at: http://www-genome.wi.mit.edu/cgibin/primer/primer3_www.cgi). The following primer sequences were used: Prohibitin: 5'-CAGCATCGGAGAGG ACTATGAT-3' and 5'-GAAGGTCAGATGTGTCAAGGA C-3'; S100A6: 5'-GTTGCTTTGAGAGGAGGACACT-3' and 5'-CCCCATAGATGATGAGAGTGGT-3'; ZNF24: 5'-A CCCAAAGAGCTACAGACTTGG-3' and 5'-CAGAACTT GGTAATCCCTGAGC-3'; EIF4A1: 5'-TGCTTAACCGGA GATACCTGTC-3' and 5'-GTCCCTCATGAACTTCTTGG TC-3'; cyclin I: 5'-GTCAGAGGTACAGCAGCCTTTT-3'

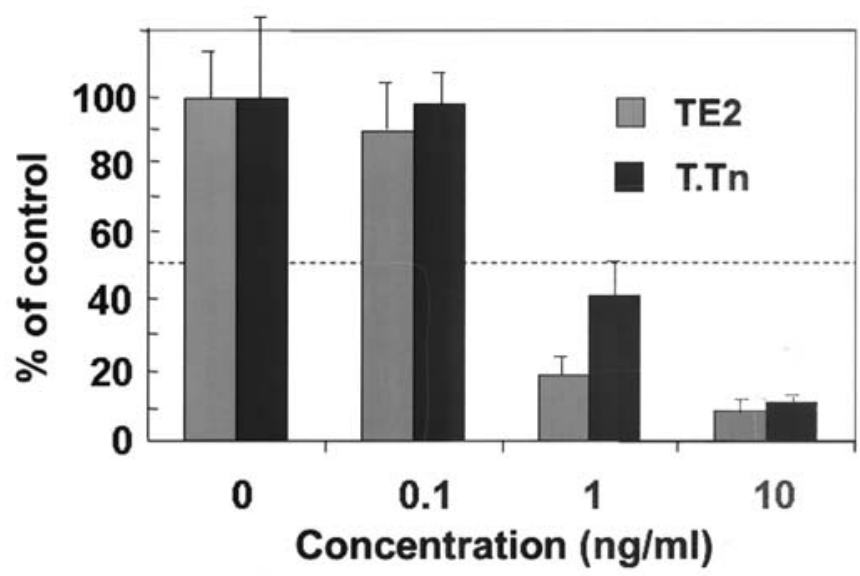

Figure 1. Effect of FK228 on human esophageal squamous cancer cell lines, TE2 and T.Tn. Cells were incubated for $72 \mathrm{~h}$ in the absence or presence of the indicated concentrations of FK228. Then, the growth inhibitory effect of FK228 was examined by Cell Counting Kit- 8 as described in Materials and methods. Data are presented as a percentage of viability in control $\pm \mathrm{SD}$ $(n=8)$.

and 5'-GAAGCATGTCCCTCTTGTCTTG-3'; GAPDH: 5'ACCACAGTCCATGCCATCAC-3' and 5'-TCCACCACCC TGTTGCTGTA-3'. The expression value was calculated as follows: expression level of each mRNA/expression level of GAPDH.

Annotation of gene function. The normalized $\mathrm{Cy} 5 / \mathrm{Cy} 3$ ratios in the microarray analysis were $\log 2$-transformed and used to classify the patterns of serial changes of the gene expression. Genes whose expression levels varied at least 2-fold at any of the time points were subjected to a hierarchical clustering analysis using the algorithm of Euclid and Ward in GeneMaths software (Applied Maths BVBA, Sint-Martens-Latem, Belgium).

The molecular functions of the genes were assigned by referring to Gene Ontology ${ }^{\mathrm{TM}}$ (www.geneontology.org/) and GeneCards $^{\mathrm{TM}}$ (bioinfo.weizmann.ac.il/cards/).

\section{Results}

FK228 demonstrated anti-proliferative activity by inducing apoptosis in human esophageal cancer cell lines. FK228 has apparent anti-proliferative activity against human cancer cells $(6-10,14)$. First, the effect of FK228 on cell growth was determined in the human esophageal cancer T.Tn and TE2 cells. A lower dose (IC50 values were 0.373 and 0.781 $\mathrm{ng} / \mathrm{ml}$, respectively) of FK228 produced changes in growth rate compared to control cells at $72 \mathrm{~h}$ in both T.Tn and TE2 cell lines (Fig. 1). In addition, our previous data (14) showed that FK228 significantly induced apoptosis.

Application of cDNA microarray analysis for detection of changes in gene expression by exposure to FK228. To examine the sequential changes in gene expression upon treatment of esophageal cancer cell lines with FK228, we performed cDNA microarray analysis. Total RNAs $(20 \mu \mathrm{g}$ each) derived from cells at 6, 12, 24, or 48 h during FK228 exposure and from control cells in duplicate were subjected to 


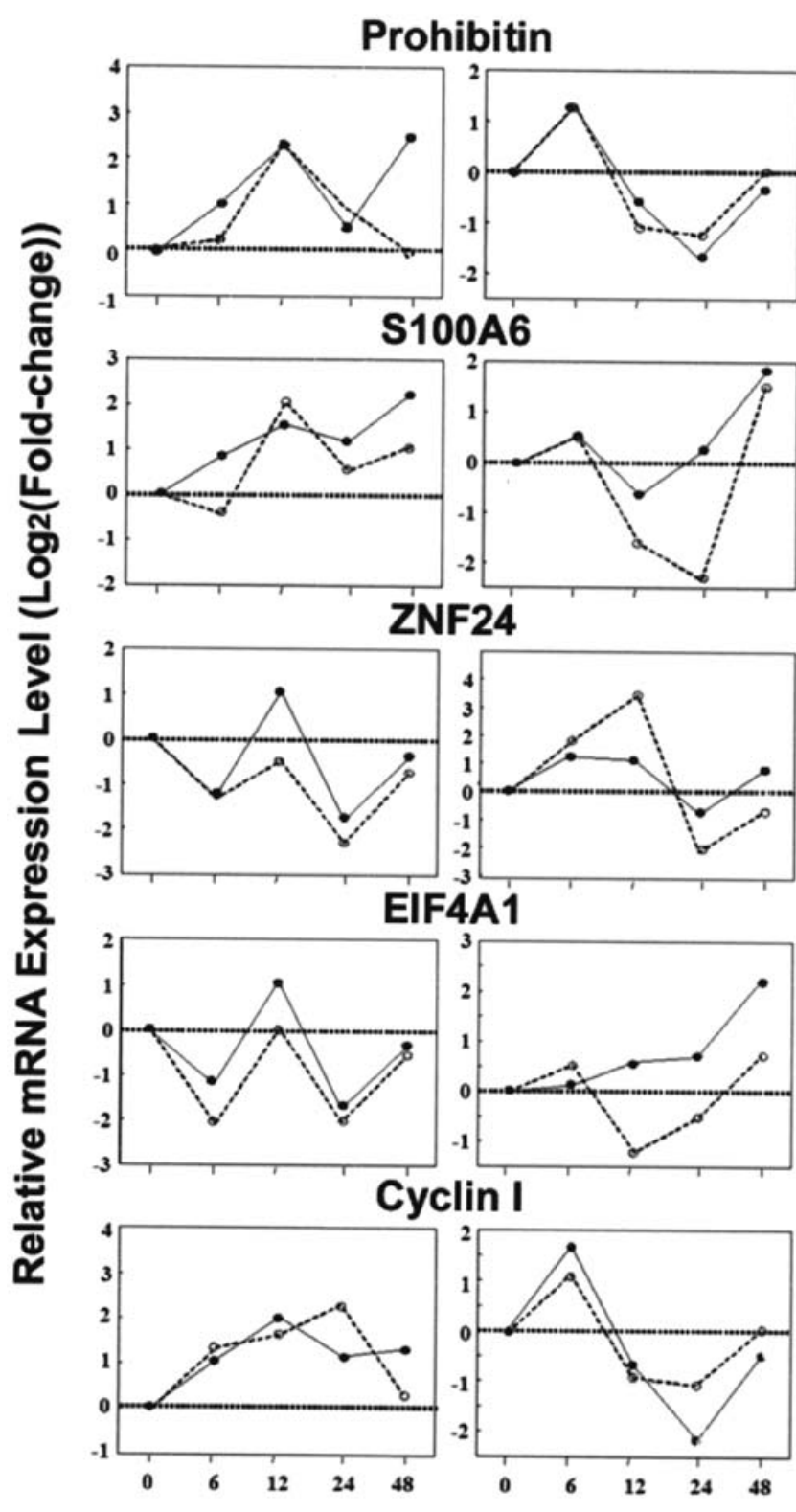

Time after Treatment of FK228 (h)

Figure 2. Comparison of results obtained with microarray and real-time quantitative reverse transcription-PCR for changes in mRNA levels after FK228 treatment. mRNA levels at various time points after FK228 treatment compared to the levels of non-treatment cells in microarray analysis (closed circles) and real-time quantitative reverse transcription-PCR analysis (open circles) are shown for the following mRNAs: prohibitin, S100A6, ZNF24, EIF4A1 and cyclin I.

Cy3 and Cy5 labeling, respectively, coupled with cDNA synthesis. Both cDNAs were mixed in equal amounts and hybridized with a microarray. Out of the 4,608 genes analyzed, we regarded the expressions of 95 genes in T.Tn and 63 genes in TE2 as meaningful, because their expression levels were altered at least 2-fold either up or down at certain points of the time course.

To confirm the validity of the results obtained by the microarray analysis, 5 randomly selected genes were examined by real-time quantitative RT-PCR analysis. The mRNA levels of these genes were nearly comparable between microarray and real-time quantitative RT-PCR, generally verifying the competency of the microarray analysis for detection of changes in gene expression during exposure to FK228 (Fig. 2).

Serial changes in expression levels of genes in relation to their functions. The 95 genes in T.Tn and 63 genes in TE2 with changes in their expression levels after FK228 exposure were subjected to clustering analysis based on their expression patterns and were classified into four clusters (Fig. 3A and $4 \mathrm{~A})$. The time course of changes in mRNA levels in each cluster can be roughly characterized as follows: cluster A, general decrease; cluster B, gradual increase; cluster C, rapid increase and persistence; cluster $\mathrm{D}$, transient up-regulation and gradual decrease (Fig. 3B and 4B).

We also categorized these genes based on their functions, referring to Gene Ontology ${ }^{\mathrm{TM}}$ and classified them into seven groups: apoptosis, cell cycles, defense and immunity, metabolism, signal transduction and transcription, structural protein and unclassified. The frequencies of these functionally classified genes in each cluster are shown in Fig. 3C and 4C.

A comparison of gene expression patterns in the two cell lines showed that 11 genes were up-regulated and 4 genes were down-regulated in both cell lines (Table I and II). Not all of these genes were classified into the same clustering groups, but fundamentally their expression patterns were similar, especially of the down-regulated 4 genes that were included in the same group.

\section{Discussion}

HDACIs, such as FK228, have become known as potent inducers of differentiation and apoptosis in cancer cells $(6,7)$. However, the mechanisms of growth inhibition by HDACIs have not been well characterized. In this study, we examined the in vitro and in vivo antitumor effects and the modulation of gene expression in human esophageal squamous cancer cells by FK228.

We showed that FK228 induces growth inhibition and apoptosis on the human esophageal cancer cell lines T.Tn and TE2. FK228 strongly inhibited the growth of T.Tn and TE2 cells in vitro. According to our previous data, a modest induction of apoptosis was observed after FK228 treatment (14).

Activities of HDACIs are required at least in part for transcriptional modulation, as this therapeutic approach is described as 'transcription therapy' (15). However, the molecular events that correlate with growth inhibition and apoptosis induction by HDACIs still remain to be proven.

The development of microarray technology has facilitated the analysis of the expression of thousands of genes in a single experiment $(16,17)$. In the present study, we used microarray analysis to find gene expression changes in response to FK228. We identified several genes that significantly upregulated in both T.Tn and TE2 cells and some of those genes have been reported as being related to cell cycle arrest or tumor suppression. The 15 genes significantly changed in both cell lines consisted of 11 up-regulated genes and 4 downregulated genes.

Cyclin-dependent kinase (CDK) inhibitor p21 WAF1 was clearly up-regulated in our data and it has been reported to 

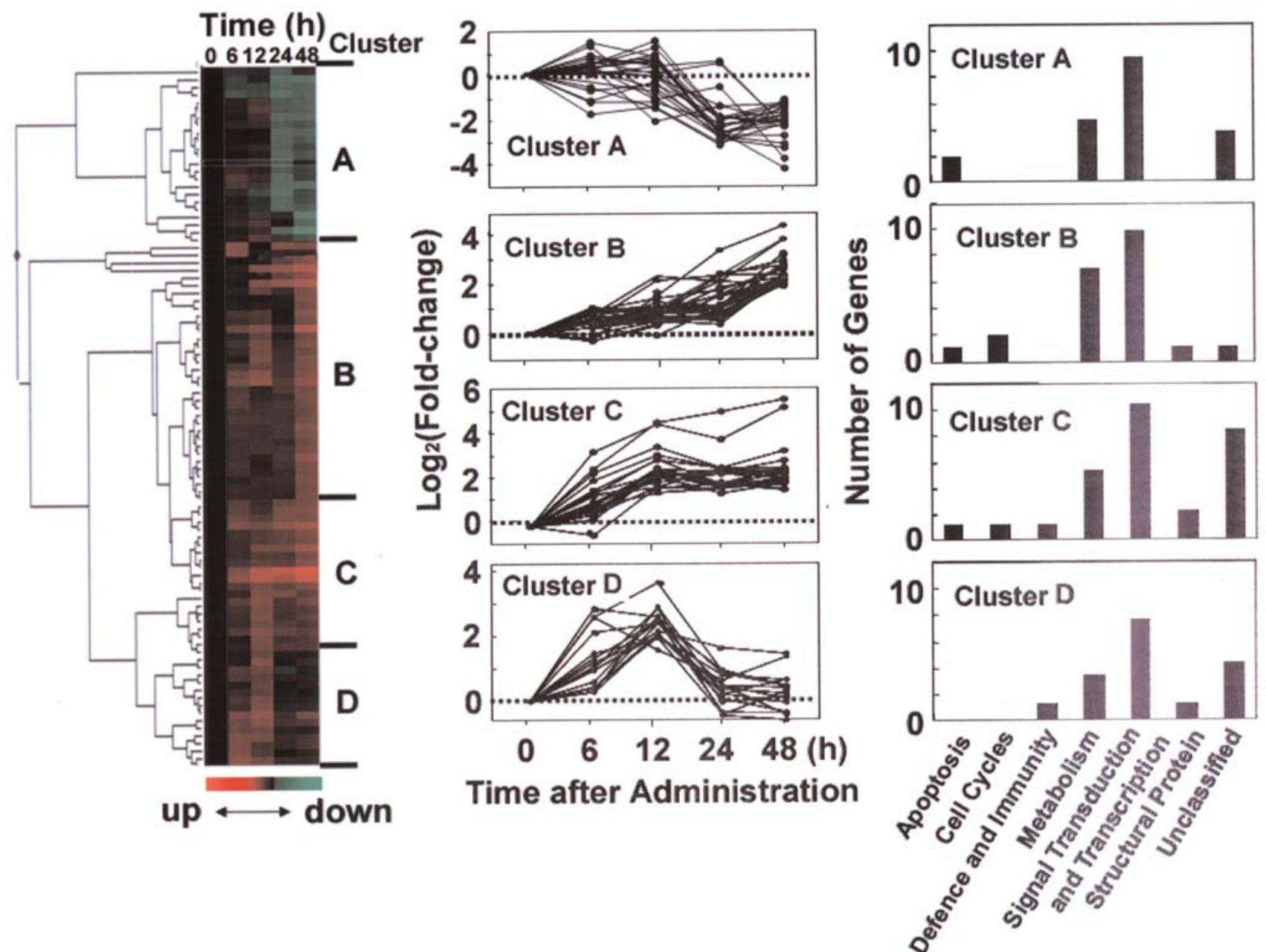

Figure 3. Gene expression profiles after FK228 treatment in T.Tn cells. (A) Cluster analysis of genes with changed expression levels after FK228 treatment. mRNA levels were assessed at 6,12, 24, and $48 \mathrm{~h}$ after treatment. A total of 93 genes whose intensities varied 2-fold or more at least at one time point were subjected to a hierarchical clustering analysis. Time points are shown in columns and genes in rows. Light red, black and light green represent the higher, equal and lower mRNA levels relative to that of the control cells, respectively. These 93 genes were classified into 4 clusters (Cluster A to D) by using GeneMaths software. (B) Expression patterns of genes in each cluster. mRNA levels of each gene at various time points after FK228 treatment relative to control mRNA levels (dotted line) in non-treatment cells are shown. (C) The distribution of functionally categorized genes in each cluster. Frequencies of genes of each functional category are shown.

play an important role in growth arrest, both in $\mathrm{G} 1$ and $\mathrm{G} 2 / \mathrm{M}$ cell cycle arrest (18). Similar to our previous results with human esophageal cancer cell lines (14), other studies revealed that HDACIs induced cell cycle arrest by regulating $\mathrm{p} 21^{\mathrm{WAF} 1}$ in some other cell lines $(19,20)$.

Peroxiredoxins (Prdx) are a novel family of $25 \mathrm{kD}$ peroxidases that can reduce $\mathrm{H}_{2} \mathrm{O}_{2}$ using an electron donor from thioredoxin and/or glutathione (21). Recently, Prdx1 was reported to inhibit c-Abl kinase activity and to regulate certain c-Myc-dependent functions and the abilities suggested that $\operatorname{Prdx} 1$ was a candidate tumor suppressor gene $(22,23)$. Neumann et al (24) had generated Prdx1-lacking mice and malignancies including digestive cancers, lymphomas and sarcomas were seen in them at a high frequency. In fact, our previous data demonstrated that the induction of Prdx 1 was correlated with the chemosensitization by FK228 (14).

EPB41, protein 4.1R (red blood cell type), has been identified as an $80 \mathrm{kD}$ protein that plays a structural role in the membrane skeleton of human erythrocytes (25). Moreover, recent studies suggest that EPB41 may have a function as a tumor suppressor. Robb et al demonstrated a loss of EPB41 expression in $40 \%$ of meningioma patients and the overexpression of EPB41 resulted in a reduction of meningioma cell proliferation (26). There are no reports on any relationship between EPB41 and esophageal cancer.

HSPA1A is one of the members of the HSP70 family that is augmented by stress response, which occurs as a result of a variety of environmental cues including heat shock, heavy metals, oxidative stress, inflammation and others (27). Rohde et al (28) found that cancer cells depleted of HSP70 and HSP70-2 (HSPA2) by small interfering RNA displayed strikingly different morphologies (detached and round vs flat senescent-like), cell cycle distribution (G2/M vs G1 arrest), and gene expression profiles. Concomitant depletion of HSP70 and HSP70-2 had a synergistic anti-proliferative effect on cancer cells. In our microarray analysis, HSPA1A expression changes were transient up-regulation and gradual decrease in both cell lines, indicating that the alteration in HSPA1A may occur as a result of the stress response by FK228.

PTRF, PolI and transcript release factor, was initially identified as a complementation of a release-deficient cellular PolI for transcript release (29). Jansa et al (30) demonstrated 

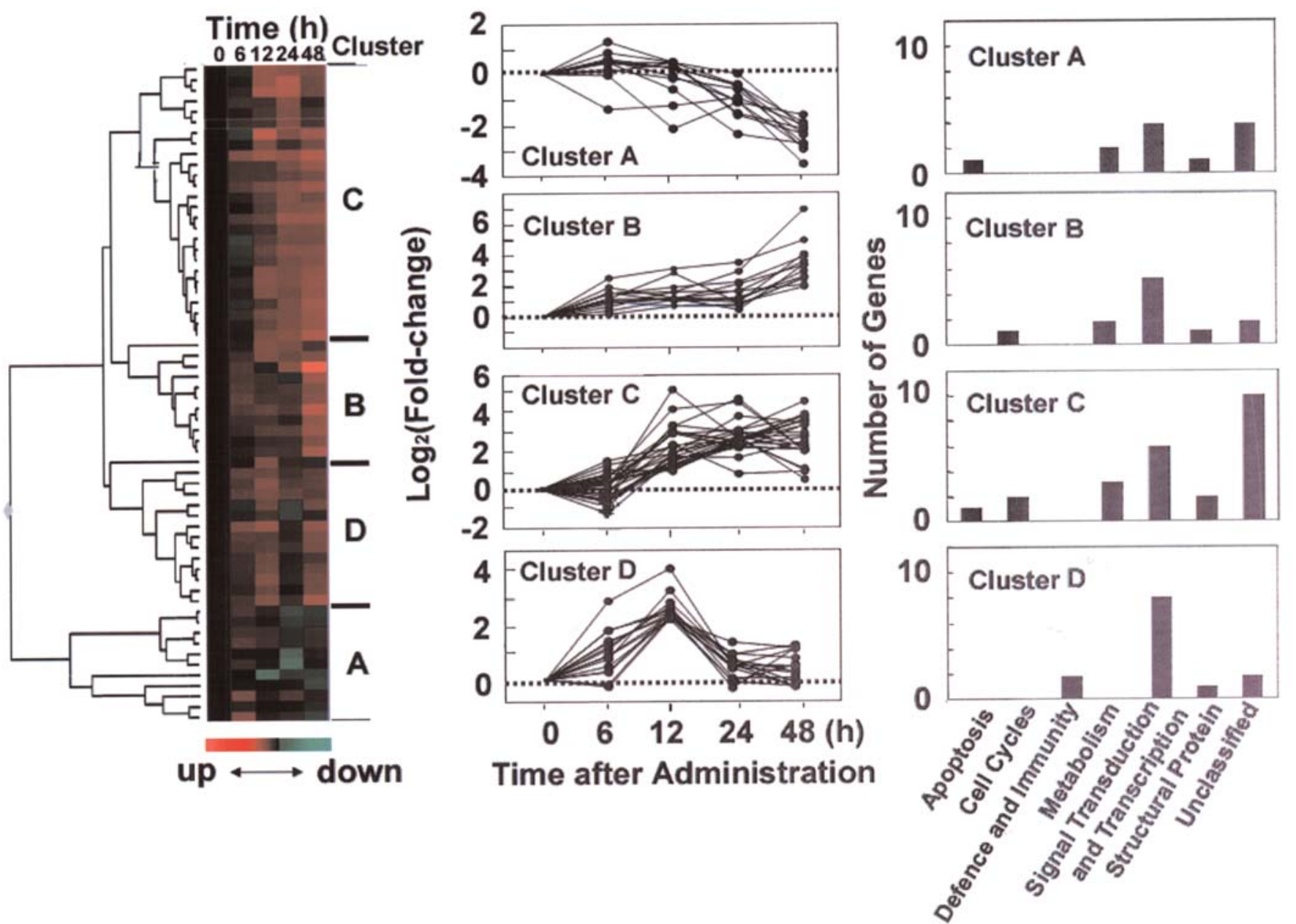

Figure 4. Gene expression profiles after FK228 treatment in TE2 cells. (A) Cluster analysis of genes with changed expression levels after FK228 treatment. mRNA levels were assessed at 6,12,24, and $48 \mathrm{~h}$ after treatment. A total of 65 genes whose intensities varied 2-fold or more at least at one time point were subjected to a hierarchical clustering analysis. Time points are shown in columns and genes in rows. Light red, black and light green represent the higher, equal and lower mRNA levels relative to that of control cells, respectively. These 65 genes were classified into 4 clusters (Cluster A to D) by using GeneMaths software. (B) Expression patterns of genes in each cluster. mRNA levels of each gene at various time points after FK228 treatment relative to control mRNA levels (dotted line) in non-treatment cells are shown. (C) Distribution of functionally categorized genes in each cluster. Frequencies of genes of each functional category are shown.

that PTRF interacts with both terminator proteins, TTF1 and PolI and binds to transcripts containing the 3-prime end of pre-rRNA in vitro. Recombinant PTRF induced the dissociation of ternary PolI transcription complexes in vitro, releasing both PolI and nascent transcripts from the template. In the situation of activating the transcription by HDACI, PTRF might be up-regulated to regulate transcriptional termination. The mechanisms of this gene in esophageal cancer cells have not been clarified.

GRN, progranulin, is a 593-amino acid glycoprotein, the mRNA of which is expressed by many epithelial cells both in vitro and in vivo. He et al (31) showed that the overexpression of the progranulin gene in adrenal carcinoma cells and nontransformed renal epithelia cells resulted in transfection-specific secretion of progranulin, acquired clonogenicity in semisolid agar and increased mitosis in monolayer culture. Progranulin is also cleaved into its component granulins, small proteins of $6 \mathrm{kD}$ and these proteins have been shown to have an inhibitory function, opposing that of progranulin. Although we have not demonstrated the role of progranulin in esophageal cancer cells with the exposure to HDACI, it might be related to the inhibition of cell growth.

PSAP, prosaposin, is a glycoprotein encoded by a single locus on human chromosome 10 and is the precursor of four sphingolipid activator proteins named saposins A, B, C and D that are localized within lysosomes and that activate the hydrolysis of sphingolipids by lysosomal hydrolases (32). In PC12 pheochromocetoma cells, prosaposin was able to activate extracellular signal-regulated protein kinases (ERKs) and sphingosine kinase (SK) with sphingosine-1-phosphate production, thus eliciting an effect of proliferation and cell death prevention (33). Prosaposin was classified into cluster B (gradual increase, Fig. 3B and 4B) meaning that it was not affected by FK228 directly, but it might be affected in some indirect manner through another protein induced by FK228.

MTATP8, ATP synthase 8 , is encoded by nucleotides of the mitochondrial genome. Mitochondria play a pivotal role in providing energy for cells and in the execution of apoptosis (34). However, the role of mitochondria in cancer is not clear. Recently, Warburg's hypothesis was supported by studies that provided a pathway by which cancer cells down-regulate 
Table I. List of 11 commonly up-regulated genes with at least two-fold change.

\begin{tabular}{|c|c|c|c|c|c|c|c|c|c|}
\hline \multirow[b]{2}{*}{ No. } & \multirow[b]{2}{*}{$\begin{array}{l}\text { Accession } \\
\text { no. }\end{array}$} & \multirow[b]{2}{*}{ Symbol } & \multirow[b]{2}{*}{ Title } & \multirow[b]{2}{*}{ Function } & \multirow[b]{2}{*}{$\begin{array}{c}\text { Cluster } \\
\text { (T.Tn/TE2) }\end{array}$} & \multicolumn{4}{|c|}{$\begin{array}{l}\text { ratio after the indicated time (h) of FK228 treatment } \\
\text { (T.Tn/TE2) }\end{array}$} \\
\hline & & & & & & 6 & 12 & 24 & 48 \\
\hline 1 & U03106 & CDKN1A & $\begin{array}{l}\text { Cyclin-dependent kinase } \\
\text { inhibitor 1A (p21, Cip1) }\end{array}$ & Cell cycle & $\mathrm{C} / \mathrm{B}$ & $2.25 / 1.98$ & $3.41 / 2.54$ & $2.32 / 2.87$ & $3.11 / 3.75$ \\
\hline 2 & X67951 & $\operatorname{Prdx} 1$ & Peroxiredoxine 1 & Metabolism/enzyme & $\mathrm{B} / \mathrm{C}$ & $0.52 / 0.44$ & $1.05 / 1.98$ & $2.24 / 2.11$ & $3.85 / 4.02$ \\
\hline 3 & M61733 & EPB41 & $\begin{array}{l}\text { Erythrocyte membrane protein } \\
\text { band } 4.1\end{array}$ & Cytoskeleton & $\mathrm{B} / \mathrm{B}$ & $0.43 / 0.98$ & $0.87 / 1.43$ & $1.12 / 1.67$ & $2.22 / 2.53$ \\
\hline 4 & M59828 & HSPA1A & $\begin{array}{l}\text { Heat Shock } 70 \mathrm{kDa} \\
\text { protein } 1 \mathrm{~A}\end{array}$ & Transcription factor & $\mathrm{D} / \mathrm{D}$ & $0.87 / 2.98$ & $2.95 / 3.74$ & $0.03 / 0.76$ & $0.01 / 0.12$ \\
\hline 5 & AK000715 & PTRF & $\begin{array}{l}\text { Polymerase I and } \\
\text { Transcript release factor }\end{array}$ & Translation factor & $\mathrm{B} / \mathrm{B}$ & $0.34 / 0.45$ & $0.98 / 1.32$ & $1.21 / 1.82$ & $2.20 / 3.24$ \\
\hline 6 & X62320 & GRN & Granulin & Translation factor & $\mathrm{C} / \mathrm{B}$ & $1.23 / 1.44$ & $3.05 / 1.98$ & $2.87 / 2.11$ & $2.65 / 3.70$ \\
\hline 7 & AL132826 & FLRT3 & $\begin{array}{l}\text { Fibronectin leucine-rich } \\
\text { transmembrane protein } 3\end{array}$ & Signal transduction & $\mathrm{B} / \mathrm{D}$ & $0.42 / 0.88$ & $0.89 / 3.01$ & $2.24 / 0.78$ & $2.51 / 0.44$ \\
\hline 8 & M81355 & PSAP & Prosaposin & Signal transduction & $\mathrm{B} / \mathrm{B}$ & $0.51 / 2.23$ & $0.92 / 2.64$ & $1.32 / 2.97$ & $2.73 / 4.52$ \\
\hline 9 & V00662 & ATP8 & ATP synthase 8 & Metabolism/enzyme & $\mathrm{C} / \mathrm{B}$ & $0.48 / 0.78$ & $0.97 / 1.11$ & $1.21 / 1.24$ & $2.22 / 2.70$ \\
\hline 10 & X93334 & ND4L & NADH dehydrogenase $4 \mathrm{~L}$ & Metabolism/enzyme & $\mathrm{D} / \mathrm{C}$ & $0.48 / 0.64$ & $2.24 / 1.82$ & $0.46 / 2.11$ & $0.52 / 3.70$ \\
\hline 11 & ВС003560 & RPN2 & Ribophorin II & Metabolism/enzyme & $\mathrm{D} / \mathrm{B}$ & $0.89 / 0.56$ & $3.30 / 0.98$ & $0.52 / 1.17$ & $0.71 / 2.36$ \\
\hline
\end{tabular}

Table II. List of 4 commonly down-regulated genes with at least two-fold change.

$\log _{2}$ ratio after the indicated time (h) of FK228 treatment (T.Tn/TE2)

\begin{tabular}{|c|c|c|c|c|c|c|c|c|c|}
\hline No. & $\begin{array}{l}\text { Accession } \\
\text { no. }\end{array}$ & Symbol & Title & Function & $\begin{array}{c}\text { Cluster } \\
\text { (T.Tn/TE2) }\end{array}$ & 6 & 12 & 24 & 48 \\
\hline 1 & ВC000013 & IGFBP3 & $\begin{array}{l}\text { Insulin-like growth factor } \\
\text { binding protein } 3\end{array}$ & Regulation of cell growth & $\mathrm{A} / \mathrm{A}$ & $-1.43 /-0.13$ & $-0.98 /-2.10$ & $-1.88 /-1.24$ & $-2.46 /-1.78$ \\
\hline 2 & ВC005391 & RPSA & $\begin{array}{l}\text { Laminin receptor } 1 \\
\text { (ribosomal protein } \mathrm{SA} \text {, } \\
67 \mathrm{kDa} \text { ) }\end{array}$ & Regulation of transcription & $\mathrm{A} / \mathrm{A}$ & $1.29 /-0.13$ & $-1.61 / 0.23$ & $-2.29 /-1.87$ & $-1.00 /-2.25$ \\
\hline 4 & $\mathrm{BC} 002355$ & HNRPA1 & $\begin{array}{l}\text { Heterogeneous nuclear } \\
\text { ribonucleoprotein A1 }\end{array}$ & Translation factor & $\mathrm{A} / \mathrm{A}$ & $0.54 / 0.54$ & $-0.19 / 0.12$ & $-2.56 /-1.14$ & $-1.72 /-3.65$ \\
\hline
\end{tabular}

mitochondrial activity (35). In kidney, colon, squamous esophageal cancer, as well as in lung, breast and gastric adenocarcinomas, expression of the ATP synthase was lower, consistent with selective repression of the expression of components involved in mitochondrial bioenergetic function. Shin et al (36) reported that ATP synthase down-regulation might lead to cellular events responsible for 5-FU resistance, so our findings may be concerned with the chemosensitization of FK228.

Fibronectin-like domain-containing leucine-rich transmembrane protein 3 (FLRT3), was localized to presynaptic axon terminals (37). Recently, Bottcher et al (38) found that FLRT3 was a novel modulator of FGF signaling. FLRT3 is a transmembrane component of the FGF signaling pathway, whose expression is regulated by FGFs and which promotes canonical FGF signaling through the MAPK pathway that is blocked by MAPK phospatase 1. FLRT was classified into cluster B or D, so this molecule might play some roles in MAPK signal transduction.

ND4L, NADH dehydrogenase 4L, is one of the 7 mitochondrial DNA-encoded subunits included among $\sim 41$ polypeptides of respiratory complex I (39). Interest in 
mitochondria with regard to neoplasia has revived, because of their role in apoptosis and other aspects of tumor biology. Polyak et al (40) found a 10563T-C transition resulting in a cys32-to-arg amino acid substitution in the MTND4L protein in colorectal cancer. Up-regulation of ND4L by FK228 might possibly be correlated with the efficacy of this drug.

Ribophorin II, one of the specific glycoproteins, spans the rough regions of the endoplasmic reticulum (RER) and is thought to play an important role either in translocation or in the maintenance of RER (41). The mammalian oligosaccharyltransferase (OST) is a protein complex composed of four rough ER-specific, type I transmembrane proteins: ribophorins I and II, OST48 and DAD1 (defender against cell death 1) (42). The DAD1 protein has been found to permit temperature-sensitive cells to escape from apoptosis. Therefore, the overexpression of one component of OST might be related to inhibiting apoptosis by this agent in esophageal cancer cells.

One of the down-regulated genes, insulin-like growth factor binding protein 3 (IGFBP3), was originally defined by the somatomedin hypothesis as the principal carrier of IGF-I in the circulation and the primary regulator of the amount of free IGF-I available to interact with the IGF-I receptor (43). However, there is accumulating evidence that IGFBP3 can also cause apoptosis in an IGF-independent manner or p53dependent and -independent fashion. However, interestingly, in some colon cancer cell lines, including SW480 and SW948, IGFBP3 also induces proliferation (44). Moreover, it has been reported that IGFBP3 mediates the TGF- $\beta 1$ proliferative response in the metastatic or highly aggressive colon cancer cell line (45). Furthermore, IGFBP3 mRNA was overexpressed in primary esophageal squamous cell carcinoma (46). From these results, the molecular functions of IGFBP3 are various and controversial. The down-regulation of IGFBP3 by FK228 should contribute to inhibiting proliferation in esophageal squamous cell carcinoma. We are currently examining the precise function of IGFBP3 in esophageal cancer cells.

Heterogeneous nuclear ribonucleoprotein D-like protein (HNRPDL) shuttles between the nucleus and the cytoplasm and the shuttling protein can interact directly with mRNA (47). Under the transcription inhibition conditions resulting in HNRPDL cytoplamic accumulation, the HNPRDL-Poly (A)+ RNA complex was found at higher levels in the cytoplasm than in the nucleus, whereas under transcriptional conditions, this complex was found in the nucleus, but not in the cytoplasm. These results suggest that shuttling HNPRDL may carry mRNA from the nucleus to the cytoplasm. However, our results indicated that HNPRDL was down-regulated and it may be unclear and even paradoxical, why HNPRDL was down-regulated under transcriptional conditions by FK228.

Heterogeneous nuclear ribonucleoprotein A1 (HNRPA1) was reported to shuttle continuously between the nucleus and cytoplasm and that it contains a 38-amino acid domain that acts as both a nuclear localization and nuclear export signal (48). These authors suggested that HNRPA1 functions as a carrier for RNA during export to the cytoplasm. Chiu et al (49) demonstrated by cDNA microarray and real-time RT-PCR that HNRPA 1 was up-regulated in colon cancer patients. Furthermore, Wei et al (50) also showed that HNRPA1 was significantly up-regulated in refractory acute leukemia patients. Presumably, HNRPA1 plays a role in the positive regulation of cancer development. Thus, down-regulation of HNRPA1 by FK228 may be associated with the cytotoxic activities of FK228 in esophageal cancer cells.

Laminin receptor 1 (RPSA) is a non-integrin protein that is co-expressed and co-regulated with the $\alpha 6$ integrin subunit and is physically associated with this integrin on the cell membrane (51). Laminin is a basement membrane glycoprotein implicated in a large number of biologic activities of cancer progression, many of which are mediated by the presence of RPSA on the cell membrane. Expression of RPSA has been reported in a wide range of carcinomas, in many of which it was correlated with poor differentiation, metastasis, disease progression and poor survival (52). This indicates that the down-regulation of RPSA should contribute to the induction of the cytotoxic effect of FK228.

Our twelve genes, except p21, Prdx1 (as reported previously) and IGFBP3, have still not been reported in terms of their behaviour or expression in esophageal cancer cells. We are investigating each of the above genes, their expression and signal transduction in esophageal cancer cells, as well as their relation to the clinico-pathological findings of surgical specimens after esophagectomy. FK228 is one of the HDACIs currently under clinical development and these preliminary results from clinical trials suggest that this agent shows great promise $(11,12)$. We are confident that our results of gene modulation profiling by FK228 in human esophageal squamous cells based on microarray analysis will lead to beneficial applications in the treatment of esophageal cancer and other carcinomas.

\section{References}

1. Miller JD, Jain MK, de Gara CJ, Morgan D and Urschel JD: Effect of surgical experience on results of esophagectomy for esophageal carcinoma. J Surg Oncol 65: 20-21, 1997.

2. Chan A and Wong A: Is combined chemotherapy and radiation therapy equally effective as surgical resection in localized esophageal carcinoma? Int J Radiat Oncol Biol Phys 45: 265-270, 1999.

3. Medical Research Council Oesophageal Cancer Working Group: Surgical resection with or without preoperative chemotherapy in oesophageal cancer: a randomised controlled trial. Lancet 359: 1727-1733, 2002.

4. Jacobson S and Pillus L: Modifying chromatin and concepts of cancer. Curr Opin Genet Dev 9: 175-184, 1999.

5. Kouzarides T: Histone acetylases and deacetylases in cell proliferation. Curr Opin Genet Dev 9: 40-48, 1999.

6. Marks P, Rifkind RA, Richon VM, Breslow R, Miller T and Kelly WK: Histone deacetylases and cancer: causes and therapies. Nat Rev Cancer 1: 194-202, 2001.

7. Johnstone RW: Histone-deacetylase inhibitors: novel drugs for the treatment of cancer. Nat Rev Drug Discov 1: 287-299, 2002.

8. Johnstone RW and Licht JD: Histone deacetylase inhibitors in cancer therapy: is transcription the primary target? Cancer Cell 4: 13-18, 2003.

9. Insinga A, Monestiroli S, Ronzoni S, et al: Inhibitors of histone deacetylases induce tumor-selective apoptosis through activation of the death receptor pathway. Nat Med 11: 71-76, 2005.

10. Henderson C, Mizzau M, Paroni G, Maestro R, Schneider C and Brancolini C: Role of caspases, Bid, and p53 in the apoptotic response triggered by histone deacetylase inhibitors trichostatin-A (TSA) and suberoylanilide hydroxamic acid (SAHA). J Biol Chem 278: 12579-12589, 2003.

11. Ueda H, Nakajima H, Hori Y, et al: FR901228, a novel antitumor bicyclic depsipeptide produced by Chromobacterium violaceum No. 968. I. Taxonomy, fermentation, isolation, physico-chemical and biological properties, and antitumor activity. J Antibiot 47: 301-310, 1994. 
12. Piekarz RL, Robey R, Sandor V, et al: Inhibitor of histone deacetylation, depsipeptide (FR901228), in the treatment of peripheral and cutaneous T-cell lymphoma: a case report. Blood 98: 2865-2868, 2001

13. Mori M, Shimada H, Gunji Y, et al: S100A11 gene identified by in-house cDNA microarray as an accurate predictor of lymph node metastases of gastric cancer. Oncol Rep 11: 1287-1293, 2004.

14. Hoshino I, Matsubara H, Hanari N, et al: Histone deacetylase inhibitor FK228 activates tumor suppressor Prdx 1 with apoptosis induction in esophageal cancer cells. Clin Cancer Res 11: 7945-7952, 2005.

15. Vigushin DM and Coombes RC: Targeted histone deacetylase inhibition for cancer therapy. Curr Cancer Drug Targets 4: 205-218, 2004.

16. Cheung VG, Morley M, Aguilar F, Massimi A, Kucherlapati R and Childs G: Making and reading microarrays. Nat Genet 21: 15-19, 1999.

17. Ramsay G: DNA chips: state-of-the art. Nat Biotechnol 16: 40-44, 1998.

18. El-Deiry WS, Harper JW, O'Connor PM, et al: WAF1/CIP1 is induced in p53-mediated G1 arrest and apoptosis. Cancer Res 54: 1169-1174, 1994

19. Archer SY, Meng S, Shei A and Hodin RA: p21 (WAF1) is required for butyrate-mediated growth inhibition of human colon cancer cells. Proc Natl Acad Sci USA 95: 6791-6796, 1998.

20. Sowa Y, Orita T, Minamikawa S, et al: Histone deacetylase inhibitor activates the WAF1/Cip1 gene promoter through the Sp1 sites. Biochem Biophys Res Commun 241: 142-150, 1997.

21. Chae HZ, Robison K, Poole LB, Church G, Storz G and Rhee SG: Cloning and sequencing of thiol-specific antioxidant from mammalian brain: alkyl hydroperoxide reductase and thiolspecific antioxidant define a large family of antioxidant enzymes. Proc Natl Acad Sci USA 91: 7017-7021, 1994.

22. Wen ST and Van Etten RA: The PAG gene product, a stressinduced protein with antioxidant properties, is an Abl SH3binding protein and a physiological inhibitor of c-Abl tyrosine kinase activity. Genes Dev 11: 2456-2467, 1997

23. Mu ZM, Yin XY and Prochownik EV: Pag, a putative tumor suppressor, interacts with the Myc Box II domain of c-Myc and selectively alters its biological function and target gene expression. J Biol Chem 277: 43175-43184, 2002.

24. Neumann CA, Krause DS, Carman CV, et al: Essential role for the peroxiredoxin Prdx 1 in erythrocyte antioxidant defence and tumor suppression. Nature 424: 561-565, 2003.

25. Takakuwa Y, Tchernia G, Rossi M, Benabadji M and Mohandas N: Restoration of normal membrane stability to unstable protein 4.1-deficient erythrocyte membranes by incorporation of purified protein 4.1. J Clin Invest 78: 80-85, 1986.

26. Robb VA, Li W, Gascard P, Perry A, Mohandas N and Gutmann DH: Identification of a third Protein 4.1 tumor suppressor, Protein 4.1R, in meningioma pathogenesis. Neurobiol Dis 13: 191-202, 2003.

27. Imai Y, Soda M, Hatakeyama S, et al: CHIP is associated with Parkin, a gene responsible for familial Parkinson's disease and enhances its ubiquitin ligase activity. Mol Cell 10: 55-67, 2002.

28. Rohde M, Daugaard M, Jensen MH, Helin K, Nylandsted J and Jaattela M: Members of the heat-shock protein 70 family promote cancer cell growth by distinct mechanisms. Genes Dev 19: 570-582, 2005.

29. Mason SW, Sander EE and Grummt I: Identification of a transcript release activity acting on ternary transcription complexes containing murine RNA polymerase I. EMBO J 16: 163-172, 1997.

30. Jansa P, Mason SW, Hoffmann-Rohrer U and Grummt I: Cloning and functional characterization of PTRF, a novel protein which induces dissociation of paused ternary transcription complexes. EMBO J 17: 2855-2864, 1998.

31. He Z and Bateman A: Progranulin gene expression regulates epithelial cell growth and promotes tumor growth in vivo. Cancer Res 59: 3222-3229, 1999.

32. Morimoto S, Martin BM, Yamamoto Y, Kretz KA, O'Brien JS and Kishimoto Y: Saposin A: second cerebrosidase activator protein. Proc Nat Acad Sci USA 86: 3389-3393, 1989.
33. Misasi R, Sorice M, Di Marzio L, et al: Prosaposin treatment induces PC12 entry in the $S$ phase of the cell cycle and prevents apoptosis: activation of ERKs and sphingosine kinase. FASEB J 15: 467-474, 2001.

34. Lin MT and Beal MF: Mitochondrial dysfunction and oxidative stress in neurodegenerative diseases. Nature 443: 787-795, 2006.

35. Isidoro A, Casado E, Redondo A, et al: Breast carcinomas fulfill the Warburg hypothesis and provide metabolic markers of cancer prognosis. Carcinogenesis 26: 2095-2104, 2005.

36. Shin YK, Yoo BC and Chang HJ: Down-regulation of mitochondrial F1F0-ATP synthase in human colon cancer cells with induced 5-fluorouracil resistance. Cancer Res 65: 3162-3170, 2005.

37. Robinson M, Parsons Perez MC, Tebar L, et al: FLRT3 is expressed in sensory neurons after peripheral nerve injury and regulates neurite outgrowth. Mol Cell Neurosci 27: 202-214, 2004.

38. Bottcher RT, Pollet N, Delius H and Niehrs C: The transmembrane protein XFLRT3 forms a complex with FGF receptors and promotes FGF signalling. Nature Cell Biol 6: 38-44, 2004.

39. Cardol P, Lapaille M, Minet P, Franck F, Matagne RF and Remacle C: ND3 and ND4L subunits of mitochondrial complex I, both nucleus encoded in Chlamydomonas reinhardtii, are required for activity and assembly of the enzyme. Eukaryot Cell 5: 1460-1467, 2006

40. Polyak K, Li Y, Zhu H, et al: Somatic mutations of the mitochondrial genome in human colorectal tumors. Nature Genet 20: 291-293, 1998.

41. Loffler C, Rao VV and Hansmann I: Mapping of the ribophorin II (RPN II) gene to human chromosome 20q12-q13.1 by in-situ hybridization. Hum Genet 87: 221-222, 1991.

42. Kelleher DJ, Kreibich G and Gilmore R: Oligosaccharyltransferase activity is associated with a protein complex composed of ribophorins I and II and a 48 kd protein. Cell 69: $55-65,1992$

43. Lewitt MS, Scott FP, Clarke NM and Baxter RC: Developmental regulation of circulating insulin-like growth factor-binding proteins in normal pregnancies and in pre-eclampsia. Prog Growth Factor Res 6: 475-480, 1995.

44. Buckbinder L, Talbott R, Velasco-Miguel S, et al: Induction of the growth inhibitor IGF-binding protein 3 by p53. Nature 377: 646-649, 1995

45. Kansra S, Ewton DZ, Wang J and Friedman E: IGFBP-3 mediates TGF beta 1 proliferative response in colon cancer cells. Int J Cancer 87: 373-378, 2000.

46. Takaoka M, Harada H, Andl CD, et al: Epidermal growth factor regulates aberrant expression of insulin-like growth factorbinding protein 3. Cancer Res 64: 7711-7723, 2004.

47. Kawamura H, Tomozoe Y, Akagi T, Kamei D, Ochiai M and Yamada M: Identification of the nucleocytoplasmic shuttling sequence of heterogeneous nuclear ribonucleoprotein D-like protein JKTBP and its interaction with mRNA. J Biol Chem 277: 2732-2739, 2002.

48. Michael WM, Choi M and Dreyfuss G: A nuclear export signal in hnRNP A1: a signal-mediated, temperature-dependent nuclear protein export pathway. Cell 83: 415-422, 1995.

49. Chiu ST, Hsieh FJ, Chen SW, Chen CL, Shu HF and Li H: Clinicopathologic correlation of up-regulated genes identified using cDNA microarray and real-time reverse transcription-PCR in human colorectal cancer. Cancer Epidemiol Biomarkers Prev 14: 437-443, 2005.

50. Wei Q, Li Y and Chen L: Genes differentially expressed in responsive and refractory acute leukemia. Front Biosci 11: 977-982, 2006

51. Gehlsen KR, Dillner L, Engvall E and Ruoslahti E: The human laminin receptor is a member of the integrin family of cell adhesion receptors. Science 241: 1228-1229, 1988.

52. Montuori N, Muller F, De Riu S, Fenzi G, Sobel ME, Rossi G and Vitale M: Laminin receptors in differentiated thyroid tumors: restricted expression of the 67-kilodalton laminin receptor in follicular carcinoma cells. J Clin Endocrinol Metab 84: 2086-2092, 1999. 